\title{
Reflexão contemporânea sobre a padronização dos Nomes Geográficos no Brasil
}

\author{
Claudio João Barreto dos Santos* \\ Moema José de Carvalho Augusto**
}

Recebido el 5 de maio de 2015; aceito el 16 de agosto de 2015

\begin{abstract}
The standardization of geographical names is a search for a suitable official denomination for each geographical feature represented in the maps and charts. Each country strives to conform, according to their own legislation so as to meet the needs of standardization of their geographical names, usually by establishing a Geographical Names Committee. This essay focuses this standardization in Brazil, and the efforts made by the Geographical Names Committee of the National Commission of Cartography (CONCAR) to reduce various issues caused by the lack of standardization.
\end{abstract}

Key words: Geographical name, standardization, official denomination, geographical feature.

\section{Resumen}

La normalización de los nombres geográficos es la búsqueda de un nombre oficial de cada accidente geográfico representado en los mapas. Cada país busca adaptar, de acuerdo con su legislación con el fin de satisfacer la necesidad de la normalización de los nombres geográficos, por lo general a partir de la creación de un Comité de Nombres Geográficos.

Esta prueba objetiva se refiere a la cuestión de la normalización de los nombres geográficos en Brasil y en los esfuerzos realizados por el Comité de Nombres Geográficos de la Comisión Nacional de Cartografía (CONCAR) para minimizar este problema.

* Coordenador do Comitê de Nomes Geográficos, Professor da Universidade do Estado do Rio de Janeiro, e-mail: cljclj6@gmail.com

** Membro do Comitê de Nomes Geográficos da CONCAR, Chefe da Delegação do Brasil UNGEGN 2006-2007, e-mail: moema.augusto@hotmail.com 
Palabras clave: Nombres Geográficos, estandarización, documentos cartográficos oficiales, características geográficas.

\section{Resumo}

A padronização dos nomes geográficos consiste na busca de uma denominação oficial para cada feição geográfica representada nos mapas e cartas. Cada país procura adaptar-se, de acordo com sua legislação, a fim de atender a necessidade de efetuar a padronização dos seus nomes geográficos, normalmente a partir do estabelecimento de uma Comissão de Nomes Geográficos.

Este ensaio foca a questão desta padronização no Brasil, e os esforços empreendidos pelo Comitê de Nomes Geográficos da Comissão Nacional de Cartografia (CONCAR) para minimizar varias questões decorrentes desta falta de padronização.

Palavras chave: Nomes Geográficos, padronização, denominação oficial, feição geográfica.

\section{Introdução ao tema}

A nominação de lugares acompanha a atividade humana desde tempos imemoriais. Nomeiam-se tanto os seres humanos, quanto os lugares, permitindo-se a individualização e a consequente identificação unívoca das pessoas e dos lugares. Mas o que vem a ser um lugar? O lugar é o quadro de uma referência pragmática do mundo de onde vem o condicionante e a ordem, e onde se instala a espontaneidade e a criatividade, onde existe um cotidiano compartido entre as mais diversas pessoas, firmas e instituições (Santos, 1996).

Porém, para esse artigo, lugar é aqui conceituado como uma ocorrência na superfície terrestre possuidor de "personalidade" própria a partir de uma prolongada vivência do homem no mesmo (Tuan, 1974).

Pode-se afirmar que o lugar insere-se num contexto de ampliação do próprio local da moradia dos indivíduos, um lar sem muros nem paredes, porém onde fica preservado o espírito de pertencimento dos moradores locais, com sentido e personalidade bem definida. Pode ser traduzido também pela ampliação do espaço conhecido, ao qual se necessita identificar de forma, em princípio, unívoca.

Detendo-se um pouco mais no conceito de lugar, torna-se digno de registro aqui nesse estudo, a análise empreendida por Relph (1976), que apresentou seis principais características componentes do conceito em tela, a saber:

I. A ideia de locação, em especial, torna-se absolutamente fundamental. Essa locação pode ser descrita em termos das características internas ao lugar e de 
interconexões com outros lugares; estabelecendo-se assim que os lugares possuem componentes espaciais internos e externos.

II. Lugares encapsulam a integração de elementos de natureza física e culturais; cada lugar possui um ordenamento próprio, singular, que sempre o distinguirá de outro lugar. Decorre daí de forma clara, que cada lugar torna-se uma entidade única, individualizada de forma inequívoca.

III. Embora os lugares sejam únicos, interconectam-se por um sistema de interações e transferências espaciais; tornando-se parte de uma rede ou teia de circulação.

IV.Lugares são localizáveis. Sendo partes (ou não) de áreas extensas, tornam-se passíveis de serem localizados e posicionados num sistema de referência geográfica.

V. Lugares surgem e transformam-se; com mudanças advindas da dinâmica histórica e cultural, novos elementos emergem e antigos desaparecem. Dessa forma os lugares possuem um inequívoco componente histórico.

VI. Os lugares possuem uma característica semântica, adquirem significados: advindos das crenças humanas.

Cada povo devido a suas especificidades culturais converte o ato de nomear num autêntico ato de registro civil, obtendo-se uma característica de singularidade na identificação das pessoas e lugares, possibilitando dessa forma, uma maior convivência na sociedade. Dick (1990) assevera que cada povo tem as suas especificações no ato de dar os nomes e na vivência dos nomes dados.

A denominação dos lugares possui uma direta relação com os deslocamentos de grupos humanos e seu possível estabelecimento sobre a superfície terrestre. Esse estabelecimento, e a necessidade de hierarquizar e identificar o ambiente à sua volta, induz o ente humano a fixar denominações para os lugares e demais feições geográficas.

Os nomes singularizam lugares, mas não os nominam ad aeternum. Existe presente nesta nominação uma evidente e clara dinâmica, que se apresenta de forma preferencial, ao sabor de injunções, sejam religiosas, políticas, econômicas, ou outras quaisquer, fazendo-os evoluir, transformar-se ou corromper-se.

Os nomes geográficos, no entanto, extrapolam, indo um pouco além de uma simples nominação. Encontram-se de forma seminal, relacionados aos jogos de poder que se superpõem, por vezes, sobre um determinado território.

O conjunto de nomes geográficos é hoje reconhecido como importante patrimônio cultural de uma nação, especialmente num contexto de redes mundiais e de proteção da propriedade intelectual de nomes únicos. Ciente de que a eficácia de muitos sistemas depende diretamente da padronização desse conjunto, a ONU realiza desde 1962, no âmbito do Conselho Econômico e Social, conferências quinquenais que produzem recomendações e estudos regulares sobre o tema. Ressalta-se que a 
ausência de padronização da toponímia gera, entre outras consequências, carência de subsídios para documentação e litígios em questões fundiárias e territoriais.

Quando o nome geográfico em sua semântica carreia de forma clara e insofismável, o poder que o gerou, a dinâmica de sua transformação é quase imediata, no caso de um antagônico poder, assumir o domínio do território em pauta. Eventualmente, essa carga de poder pode não se mostrar tão explícita na semântica geonímica, como àqueles cujas motivações são vegetais, minerais ou animais. Nesse caso, o nome geográfico tenderá a transformar-se num fóssil linguístico, pois sua perenidade pode, em contrapartida, aproximar-se de uma escala de tempo milenar.

A área do conhecimento científico que engloba o estudo dos nomes geográficos é a Onomástica, que consubstancia-se no estudo dos nomes próprios. Esta área do conhecimento divide-se em duas outras: Antroponímia e Toponímia. A Antroponímia é o estudo dos nomes de pessoas e a Toponímia o estudo dos nomes dos lugares, área do conhecimento humano na qual, insere-se o presente estudo. Como descendente direta da Onomástica, considera-se também chamá-la Toponomástica. Dick (1990).

\section{A necessidade da padronização dos nomes geográficos}

A Tradição é o fundamento para a manutenção de um nome geográfico para que se mantenha inalterado por gerações de falantes. Caso exista tradição, a grafia deve ser mantida intacta.

Nesse contexto, o item 42 das Instruções para a Organização do Vocabulário Ortográfico da Língua Portuguesa da ABL, dispõe o seguinte:

Os topônimos de tradição histórica secular não sofrem alteração alguma em sua grafia, quando já esteja consagrada pelo consenso diuturno dos brasileiros. Sirva de exemplo o topônimo "Bahia", que conservará esta forma quando se aplicar em referencia ao Estado e à cidade que tem esse nome. Atendendo ao disposto neste item, deverá manter-se a grafia de outros nomes próprios "de tradição histórica secular". Essa abertura na legislação da ABL, se mal aplicada, pode acarretar desmandos, do ponto de vista dos lexicógrafos, ao considerá-la demasiadamente elástica, quando não se considera a expressão "sirva de exemplo o topônimo Bahia", como um caso limite.

O termo tradição vem do latim tradere, ou seja, transmissão, tradere = entregar. Aceita-se o conceito de tradição nesse estudo, ao entendê-lo como a transmissão ou entrega de valores de uma geração à outra. Em outras palavras, consubstancia-se como uma transmissão oral de lendas ou narrativas ou de valores espirituais de geração em geração. 
Uma crença de um povo, algo que é seguido conservadoramente e com respeito através das gerações. Uma recordação, memória ou costume; uma orientação para o passado, de tal forma que o passado tem uma pesada influência ou, mais precisamente, é constituído para ter uma pesada influência para o presente.

Um nome geográfico, portanto, que consiga ter a sua grafia incólume ao atravessar mais de uma geração, é um nome aceito como correto pelo critério da tradição, mesmo que sua ortografia encontre-se equivocada, quando considerado o padrão ortográfico vigente no país. É um critério que, por ser muito importante é, por vezes fácil, por outras, de difícil aplicabilidade. Deve ser utilizado com extremo cuidado, a fim de que não se corra o risco de confundir, nomes geográficos tradicionais com anacronismos ortográficos.

Fácil quando se sabe que no Brasil, por tradição, denomina-se por exemplo: Alemanha e não Deutshland; Inglaterra e não England; Buenos Aires e não Bons Ares; Munique e não München; Estado da Bahia e não Estado da Baía; Magé e não Majé etc. Nesses casos, não há muito o que discutir, pois existe o respaldo da tradição, desde algumas gerações, de assim denominar as feições geográficas exemplificadas, mesmo que em alguns casos como Magé e Bahia, ocorram equívocos em relação ao padrão ortográfico vigente no país.

Difícil quando é necessário decidir, se existe ou não tradição no Brasil, ao chamar New York de Nova Iorque ou Nova York ou mesmo New York; Caxemir, Cachemira ou Caxemira; Singapura ou Cingapura; Madri ou Madrid; Strasburgo ou Estrasburgo; Viet Nam ou Vietnã; Amsterdam ou Amsterdã; Camarões ou Cameroon; Paraty ou Parati; Paty do Alferes ou Pati do Alferes; Quissaman, Quiçamã ou Quissama, etc.

Mais que difícil, pode se tornar perigoso, se alguém em nome do conceito da tradição, resgata a forma de grafar nomes geográficos como Nictherói, em detrimento à atual Niterói. Do ponto de vista desse ensaio, o conceito de tradição não estaria sendo bem aplicado.

Faz-se necessário uma instituição que coordene e ajude a dirimir tais dúvidas, além de discernimento para que se faça a correta separação entre os falares regionais tradicionais não passíveis de correções, com os anacronismos gramaticais, estes sim, com a obrigação e o dever de serem corrigidos, a fim de não se transformarem em teratomas lexicais.

No primeiro caso, cite-se o caso de córguinho, corruptela de córregozinho, que é um falar regional do Estado do Paraná, e Crôa, corruptela da feição hidrográfica Coroa, esse, um falar regional do Estado do Ceará. No segundo caso, podemos citar: Fasenda São Juzé ao invés de Fazenda São José; Fasenda Três Irmão ao invés de Fazenda Três Irmãos; Rua Pampocha ao invés de Rua Papoula.

Faz-se necessário, portanto, a devida separação entre falar regional tradicional com anacronismos gramaticais, em outras palavras, erros ortográficos da língua portuguesa. 
Nesse ponto há que deter-se, ainda um pouco mais, no conceito da padronização. O que viria a ser afinal, um nome geográfico padronizado? Não é uma questão que tenha uma resposta direta e trivial.

A princípio não existe diferença conceitual entre normalização - regularização, retorno a uma situação normal, ato de normalizar (tornar normal; normativo - de que se tiram regras ou preceitos, que tem força de regra ou norma (principio que serve de regra ou de lei modelo, exemplo) e padronizar - estabelecer o padrão de, servir de modelo, estandardizar, estabelecer padrões, normas ou modelos (Koogan/Houaiss, 1995). Sob o ponto de vista desse estudo, fica evidente a sinonímia entre os termos normalizar, normatizar e padronizar.

A preferência, aqui, pelo termo padronizar, recai no fato da presença nos textos sobre nomes geográficos da ONU, da palavra standard, traduzida como padrão na língua portuguesa.

Entende-se, portanto, por padronizar um nome geográfico, o fato de que quando houver a ocorrência de vários alônimos — cada um de um ou mais geônimos referidos a uma mesma feição geográfica - um deles deve ser marcado de forma explícita como nome oficial, e sua grafia fixada de acordo com as normas em vigor, de preferência sancionado por uma Comissão em nomes geográficos.

Convive-se nos dias de hoje com sérios problemas em relação a falta de padronização dos nomes geográficos, com demandas judiciais que costumam por vezes chegar ao Supremo Tribunal Federal por questões relacionadas a falta de padronização dos mesmos nos documentos cartográficos oficiais, principalmente quando nomeiam áreas que fazem parte da divisão geopolítica administrativa em termos nacionais (distritos, municípios e estados) além das questões internacionais.

A falta de padronização dos nomes geográficos causa muito desconforto em questões como: comunicação, entendimento, tempo e dinheiro. A questão das localizações geográficas protegidas em razão de arranjos produtivos locais de caráter coletivo é um exemplo candente dessa necessidade, entre tantas outras. A normalização de topônimos segundo as regras internacionais poupa dinheiro ao país, é importante economicamente, socialmente e administrativamente.

Faz diferença fundamental até na velocidade e efetividade da comunicação internacional e no envio de assistência no caso de catástrofes naturais ou crises humanitárias. Promove o desenvolvimento de inúmeras atividades, como a cartografia, o planejamento urbano e regional, a defesa nacional, a navegação, o comércio, as tradições culturais e a prevenção de emergências.

Para a ONU o uso preciso dos nomes geográficos padronizados e referenciados é elemento essencial para a eficiência das comunicações mundiais. A padronização contribui para o desenvolvimento socioeconômico, a gestão ambiental e a infraestrutura dos países. Essa foi a razão pela qual a ONU criou o Grupo de Especialistas das Nações Unidas em Nomes Geográficos (UNGEGN). UNGEGN 
fomenta em todo o mundo o uso preciso de nomes geográficos padronizados e referenciados.

\section{O Comitê de Nomes Geográficos da Comissão Nacional de Cartografia (CONCAR) e algumas tratativas de padronização dos nomes geográficos}

No Brasil, segundo a Constituição Federal de 1988, compete privativamente à União legislar sobre os sistemas: estatístico, cartográfico e de geologia nacionais. Nesse sentido é identificado o Ministério do Planejamento, Orçamento e Gestão (MP), como gestor do Sistema Cartográfico Nacional (SCN), e para isso conta com a assessoria da Comissão Nacional de Cartografia (CONCAR). A CONCAR é um órgão normatizador e aglutinador de uma série de instituições, com a finalidade de prover o Estado brasileiro de informações para os tomadores de decisão em geral, construindo e gerando dados e informação geoespaciais.

A considerar que os Nomes Geográficos configuram importante camada de informação geoespacial, a sua padronização é fundamental. Em 2008 foi criado na CONCAR o Comitê de Nomes Geográficos do Brasil (CNGEO), com o objetivo de promover esta padronização dentro do território da República Federativa do Brasil, assim como dos nomes estrangeiros que serão inseridos em produtos cartográficos nacionais. No âmbito do trabalho do CNGEO estão sendo propostos os seguintes princípios (em fase de apreciação pela CONCAR):

I. Respeitar as normas do direito interno do país e do direito internacional emanadas da ONU;

II. Respeitar as normas ortográficas da língua portuguesa, admitindo-se, excepcionalmente, alteração de grafia levando em consideração o uso tradicional do nome geográfico em função das origens culturais específicas, observando o uso de línguas nativas ou estrangeiras da tradição local;

III. Respeitar a tradição local do nome geográfico, avaliando o seu contexto regional e nacional;

IV. Rejeitar o uso de nomes pejorativos ou ofensivos;

V. Evitar o uso de nomes duplicados em diversos elementos geográficos que possam causar equívoco para sua identificação. Criar formas e critérios de diferenciação ou limitação;

VI.Evitar a alteração do nome geográfico;

VII.Considerar oficiais os nomes geográficos formalmente emanados dos Poderes Executivo e Legislativo competentes, em suas diversas instâncias;

VIILConsiderar apenas um nome oficial para cada elemento geográfico passível de representação no território do Brasil;

IX. Reconhecer o Ministério das Relações Exteriores (MRE) do estado brasileiro como a instituição responsável pela palavra final nas questões envolvendo 
litígios de nomes geográficos entre países, assim como no caso dos nomes identificados nas fronteiras referentes aos limites internacionais do Brasil.

Um exemplo prático da participação do MRE no CNGEO foi a resolução CONCAR 01/2015, sobre a adoção pelo Brasil da nomenclatura Ilhas Malvinas, Geórgia do Sul e Sandwich do Sul. Esse caso foi um exemplo vívido o sabor políticodiplomático da toponímia no cenário internacional, acentuando-se sempre que estão em jogo questões de soberania nacional. Na medida em que reflete a cultura, a história, a identidade de um país, a toponímia é questão de alta relevância política. Diante das injunções diplomáticas inerentes à toponímia estrangeira, muitas Chancelarias têm desempenhado papel preponderante na matéria.

Essa resolução foi baseada numa Declaração emitida pelo MRE em junho de 2013, baseada em questões diplomáticas, pois o Brasil apoiou os direitos da Argentina na disputa de soberania com o Reino Unido sobre as Ilhas Malvinas e coaduna-se com as manifestações do MERCOSUL, da LTNASUL e da CELAC conclamando as Partes a retomarem o diálogo.

Resulta no entendimento que no Brasil, da mesma maneira, instituições como o IBGE e a ABNT, e mais recentemente a CONCAR, têm reconhecido a competência do Itamaraty no assunto e solicitaram-lhe, em mais de uma oportunidade, que se fizesse representar em comissões sobre padronização de topônimos estrangeiros.

\section{Considerações finais}

Em última instância, a padronização dos nomes geográficos consubstancia-se em nada mais, nada menos, do que se procurar obedecer à lei áurea intrínseca a Geonímia, a qual reza: a cada nome geográfico deve corresponder apenas uma identificação fonética (respeitando-se as diferenças de acentos regionais) e uma grafia.

A sociedade moderna depende do uso de nomes geográficos padronizados, a fim de garantir uma administração e comunicação precisa e eficiente. Um programa de padronização nacional poupa tempo e recursos financeiros, ao incrementar a eficiência operacional em todos os níveis do governo, indústria, comércio e educação.

Isto se torna singularmente concreto na produção de mapas e gráficos; operações de censo; defesa nacional; comunicação terrestre, aérea e marítima doméstica e internacional; pesquisas aquáticas e minerais; entregas postais e frete; segurança por terra e mar; controle de desastres ambientais, busca e salvamento, preparação de emergências; projetos da área cultural, social e científica.

Os processos de padronização nacionais tendem a eliminar a duplicação de trabalho, quando mais de um órgão ou organização identifica e utiliza o uso correto e consistente dos nomes geográficos padronizados. 
De importância crucial, os povos de uma nação identificam nos nomes geográficos uma parte essencial de sua herança cultural.

Um Comitê ou Comissão em nomes geográficos de âmbito nacional também fornece a cada país os meios para estabelecer seus próprios nomes, tornando-os oficialmente aceitos, em contraponto ao fato dos mesmos serem determinados de maneira enviesada, muitas das vezes baseados em critérios ditados pelo senso comum num mapa oficioso, atlas ou produtores de gazetteers não-governamentais ou internacionais.

A padronização de nomes geográficos varia de um país para outro. Na verdade, nem mesmo dois países com programas eficazes abordam a padronização da mesma forma e sua organização, princípios, diretrizes e procedimentos variam muito.

Nenhum método é melhor do que outro, desde que cada um atinja a meta de estabelecer nomes escritos que sejam nacionalmente aceitos e acordados de forma consistente (salvo raras exceções) com o uso local falado e escrito.

\section{Bibliografía}

Brasil (1989). Constituição da República Federativa do Brasil, de 5 de outubro de 1988. São Paulo, Atlas, 200 pp.

Brasil, "Decreto-lei n. 243, de 28 de fevereiro de 1967. Fixa as Diretrizes e Bases da Cartografia Brasileira e dá outras providências", Diário Oficial [da] República Federativa do Brasil, Brasília, DF, 28 fev. 1967.

Toponímia e Antroponímia no Brasil. Coletânea de Estudos (1990). $2^{\mathrm{a}}$ edição, São Paulo.

Coutinho, R.P. (1999). "Tese do Curso de Altos Estudos”, Instituto Rio-Branco, Ministério das Relações Exteriores.

Dick, M.V.P.A. (1990) A motivação toponímica e a realidade brasileira, Geo Arquivo do Estado São Paulo.

Koogan, Houaiss (1995). Enciclopédia e Dicionário Ilustrado, Edições Delta, Rio de Janeiro.

Nações Unidas (2015). "UNGEGN Brochure”, <http://unstats.un.org/unsd/geoinfo/ UNGEGN/docs/pubs/UNGEGNbrochure_por.pdf>, acessado em julho de 2015. Relph, E. (1976). Place and Placenessless, Pion, London.

Santos, C.J.B. (2008). "Geonímia do Brasil: A Padronização dos Nomes Geográficos num Estudo de Caso dos Municípios Fluminenses". Tese. Universidade Federal do Estado do Rio de Janeiro (UFRJ), Rio de Janeiro.

Souza, M.J.L. (1995). "O Território: Sobre Espaço e Poder, Autonomia e Desenvolvimento", Geografia: Conceitos e Temas. Organizado por: Iná Elias de 
142 Claudio João Barreto dos S. e Moema José de Carvalho A. $\quad$ Reflexão contemporânea sobre...

Castro, Paulo César da Costa Gomes, Roberto Lobato Corrêa, Bertrand Brasil, Rio de Janeiro.

Tuan, Yu-Fu (1974). "Topofilia: Um estudo da percepção, estudos e valores do meio ambiente", Trad. Lívia de Oliveira, Difel Difusão Editorial S.A., São Paulo. 